\title{
MORIR EN UN HOSPITAL. REFLEXIONES Y COMENTARIOS A LA OBRA DE PHILIPPE ARIÉS
}

\author{
José Luis Díaz Agea
}

Profesor Escuela U niversitaria de Enfermería. U CAM . M urcia.

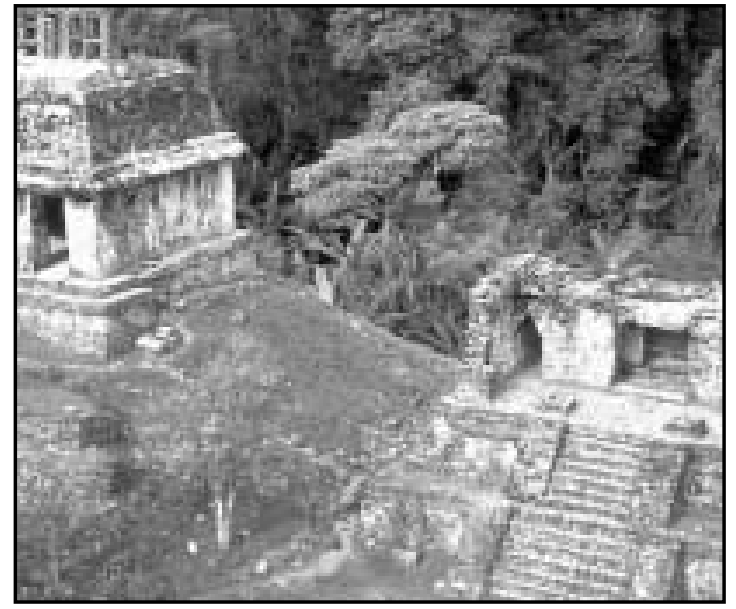

DYING IN A HOSPITAL. REFLECTIONS AND COMMENTS ON PHILIPPE ARIÉS' WORK

\section{ABSTRACT}

$\mathrm{T}$ The denial of death and the suppression of any cultural trace of it, outside TV or theatre, is a fact that should but does not surprise us. We are born and we die under an authorized and technical professional control; we are supervised as we arrive and as we leave this world. Once, to die was a normal event and not a tragedy or a traumatic fact as it is nowadays. People waited for the moment of death with a submission and an understanding approach. People knew the unequivocal sings of the moment of death. Why can't we bear the vision of death? Why do we entrust this moment to hospitals and health care institutions? In this essay, with Philippe Ariés' ideas as a starting-point, I will expose some of the notions and opinions about today's most common way to die (which is in a hospital), about medical power, our everyday progressive medicalisation and the nursing role in the process of "dying in hospital".

Key words: Death, medicalisation, suffering, palliative care, ethics, Philippe Ariés, Nursing

\section{RESUMEN}

T a negación de la muerte y la supresión de todo rastro cultural de la misma fuera de lo meramente teatral o televisivo es un hecho que debiera sorprendernos, pero que no suele despertar mayores sospechas. Se nace y se muere bajo la supervisión de un profesional técnicamente facultado para apadrinar y manejar nuestra aparición y nuestra despedida de la función. Hubo épocas en las que no resultaba tan trágico ni tan traumatizante este hecho natural, se esperaba su llegada en actitud más o menos comprensiva, se sabían los signos inequívocos de su aparición ¿Por qué no soportamos la visión de la muerte y se confía su manejo a las instituciones sanitarias? Tomando como punto de partida la obra de Philippe Ariés se esbozarán algunas ideas sobre las que parece interesante meditar en el contexto de la progresiva medicalización de la vida cotidiana y se reflexionará acerca del papel de la enfermera en el proceso de la "Muerte hospitalaria".

Palabras clave: Muerte; Medicalización; Sufrimiento; Cuidados Paliativos; Ética; Philippe Ariés; Enfermería.

\section{INTRODUCCIÓN}

"La muerte induce a la rebeldía contra la vida y el destino.

¿Por qué están limitados mi conocimiento, mi talla?

¿Por qué la duración de mi vida puede ser de cien años y no de mil?"

(Blaise Pascal).

Durante el desarrollo de la profesión enfermera no es infrecuente tratar cara a cara con la muerte del otro. Asimismo se ha convertido en un hecho completamente asumido e interiorizado por la población general: El hospital es el lugar moderno para terminar nuestros días. Curioso espacio dónde se dan cita los acontecimientos más trascendenta- 
les de nuestra existencia; allí dónde nuestros ojos ven la luz por vez primera seguramente también se apagarán ante la más o menos atenta mirada de un funcionario que no nos conoce de nada o, con menos suerte, en auténtica soledad. No es dramatismo ni exageración, créanme, si esta afirmación pesimista la comparamos con la forma de morir premoderna que describiré en este artículo basándome en la obra del historiador francés Philippe Ariés.

La negación de la muerte y la supresión de todo rastro cultural de la misma fuera de lo meramente teatral o televisivo es un hecho que debiera sorprendernos, pero que no suele despertar mayores sospechas. Se nace y se muere bajo la supervisión de un profesional técnicamente facultado para apadrinar y manejar nuestra aparición y nuestra despedida de la función.

Cuando cayó en mis manos la obra de Ariés sobre el sentido y las prácticas funerarias en Occidente advertí que era necesaria su difusión entre la comunidad enfermera como un elemento útil de reflexión a la hora de poseer herramientas que sirvan para evaluar en profundidad nuestra labor. La progresiva medicalización de la vida cotidiana es una cuestión ya tratada por intelectuales atrevidos desde Illich hasta Foucault que todavía preocupa a ciertos sectores críticos con la forma de manejar y monopolizar la salud y la enfermedad. Cada vez aparecen más voces que se silencian (habría que preguntarse por qué es imposible encontrar en una librería "Némesis médica"), libros que pasan desapercibidos o trabajos desde el nuevo y enriquecedor ámbito de la asociación antropología/enfermería (como la Medicina bajo sospecha de Gálvez Toro) que claman por otra visión de la práctica asistencial, fuera de los juegos de poder y autoridad que hasta ahora han condicionado el universo sanitario occidental, tecnificado y deshumanizado.

¿Por qué no soportamos la visión de la muerte y se confía su manejo a las instituciones sanitarias? Tomando como base y punto de partida dos libros de Philippe Ariés (Historia de la muerte en occidente y El hombre ante la muerte) trataré de esbozar algunas ideas sobre las que parece interesante meditar.

\section{Cómo moríamos y como morimos. La muer- te domada y la muerte vedada.}

Durante miles de años el hombre ha mirado cara a cara a la muerte. Hoy se le da la espalda con la falsa idea de que así será menos traumática la despedida, o con la moderna ilusión derivada del mercado en la que somos eternamente jóvenes. La actitud antigua de esperar la llegada de la muerte en la cama, con el enfermo rodeado de sus conocidos y familiares en una suerte de ceremonia pública ritualizada hace tiempo que pasó a la historia. A cualquiera que se le preguntase hoy día sobre la conveniencia de que los niños estuviesen presentes en la habitación del moribundo abuelo se rasgaría las vestiduras. ¡Qué horror! Curiosamente hasta el siglo XVIII los niños siempre aparecen en las representaciones de las habitaciones en las que se está muriendo alguien.

A la familiaridad con la que se afrontaba la hora final en la Edad Media, por ejemplo, Ariés le llama "Muerte domesticada". Por supuesto que nadie se perdía el espectáculo de la despedida y a nadie se le privaba de "vivir" intensamente este momento, considerado sagrado, de transición entre una vida y otra. Aunque también es cierto que siendo asumida dentro de la cotidianeidad no estaba exenta de carga negativa y miedo.

Curiosamente las actitudes frente a la muerte determinan, según este autor, la pasión por la vida del hombre de finales de la Edad Media, que se sabe finito. El hombre precapitalista, con una esperanza de vida más corta que hoy en día, sentía verdadero amor por la vida terrenal, por lo efímero.

La propia muerte también se vivía de forma diferente a lo que hoy tenemos por costumbre. Hubo épocas en las que no resultaba tan trágico ni tan traumatizante este hecho natural, se esperaba su llegada en actitud más o menos comprensiva, se sabían los signos inequívocos de su aparición(no era un saber técnico ni médico sino popular, al alcance de todos, porque todos habían experimentado alguna vez la muerte del otro). Dice Ariés "No se moría uno sin haber tenido tiempo de saber que iba a morir"(Ariés. 2000. p 24). Esta preparación lógica es de la que gran parte de los moribundos actuales están desprovistos; se les está privando sin duda de su propia muerte con la intención de proteger y esconder la gravedad de su estado. Se deposita la responsabilidad de decidir la información en la 
figura del médico, ahora los signos inequívocos de la muerte pasan a ser un saber científico.

\section{Nacer y morir. Dos momentos medicalizados (¿secularizados?).}

En nuestros hospitales se está privando a los sujetos de su propia muerte. Morir se ha convertido en un proceso patológico más sobre el que la medicina ha construido sus indicaciones y contraindicaciones. En relación con los efectos de la medicalización de la vida cotidiana es interesante incluir el comentario de Márquez y Meneu calificando nuestra sociedad occidental: "Una sociedad donde ya todos los niños nacen por cesárea, la gente está insegura sobre si es normal o no en sus relaciones sexuales, el miedo a la enfermedad se ha apoderado de todos, y casi nadie se muere con un poco de paz." (Márquez. 2003).

Como todos las ámbitos de la vida cotidiana que se medicalizan, también el momento de la muerte (de carácter sagrado para prácticamente todas las culturas incluida la nuestra - sin ser ni mucho menos homogénea-) se patologiza y describe científicamente en fases, síntomas, signos, etc. Uno no está muerto de verdad hasta que no lo sentencia el facultativo. "Quiero un electro de tira plana".

Como expresa acertadamente Ariés refiriéndose al médico y a su equipo: “...Son ellos los dueños de la muerte, del momento y también de las circunstancias de la muerte..."(Ariés, 2000 p. 86). Para dilucidar las consecuencias de la privación en el individuo de su propia muerte hay que indagar en el pasado y en las vivencias religiosas de una época pretérita. Antiguamente la muerte solía (y debía) ser previsible(Pública)y muy rara vez súbita(este hecho se consideraba terrible, ya que privaba al sujeto de la preparación oportuna, del arrepentimiento, la confesión, de estar en paz con Dios y el mundo). La visión secularizada del ser humano que ofrece la modernidad y que hereda la ciencia médica resta importancia a los aspectos anteriormente mencionados para centrar sus esfuerzos en la recuperación funcional del cuerpo, del órgano; y cuando esto no es posible parece que no hay nada más que hacer. El hecho que era público se silencia, lo que era conocido por el moribundo se le oculta, se elude esa información como un deber moral del médico y la familia: No se le pueden amargar los últimos momentos informando de la gravedad de su estado. "Las nuevas costumbres exigen que muera en la ignorancia de su muerte" (Ariés 2000 p. 231).

Si analizamos la cuestión de la toma de decisiones la familia pasa a desempeñar un papel preponderante que anteriormente pertenecía al sujeto moribundo. Ahora se considera a éste un incapacitado y por lo tanto un sobreprotegido. Es como un menor de edad o un discapacitado mental, hay que decidir por él. Si a ello unimos que las fronteras de la muerte hoy día resultan imprecisas y que enfermedades terminales como el cáncer son profundamente estigmatizadoras (equiparables e identificables con la misma muerte), se puede afirmar que existe un rechazo a comunicar lo inevitable. Echando mano de las posibilidades casi milagrosas de la medicina se mantiene al enfermo en un estado de desinformación. Así la discreción se asimila con lo "digno".

Para Philippe Ariés, la postergación de la información a la familia y la negación a la hora de advertir al enfermo por parte de los médicos (y curiosamente en menor grado por las enfermeras, más reticentes a ocultar información)se debe al miedo a perder el control al verse involucrados en una serie de reacciones sentimentales que deslocalizan a los profesionales del roll que desempeñan.

El dramatismo se evita a toda costa, esa tensión emocional se elude, la conmoción y la exageración pondrían en peligro la tranquilidad del hospital. La muerte resulta ciertamente embarazosa. Aún en el caso en el que el paciente sepa que va a morir se le exige (no explícitamente, claro está)que lo lleve con discreción, como si en realidad no lo supiera. Lo fundamental es no perturbar el funcionamiento institucional.

\section{El antiguo tabú (sexo) y el nuevo tabú (muerte).}

Morirse y que se mueran da miedo. La muerte da miedo, según Ariés "hasta el punto de que ya no nos atrevemos a pronunciar su nombre" (Ariés 2000 p 33). Es quizá el objeto de tabú más importante de la actualidad, sustituyendo al tabú sexual en el ranking. En el lenguaje formal aparece maquillada de eufemismos o silencios. El origen de este silencio que envuelve al tema del adiós es precisamente la mentira generada en primera instancia para proteger al individuo de su propia 
muerte y a la sociedad del sufrimiento que supone la muerte del otro. La carga dramática de la muerte en casa, en la propia cama, se diluye en la institución hospitalaria. Los inconvenientes de la primera forma se solventan en el hospital, se tecnifica el momento. Ya no es el resultado y la consecuencia lógica de existir, sino más bien el cese de los cuidados por decisión médica basándose en una serie de estudios que determinan de qué tipo de muerte se trata. La posibilidad de reanimación hace impreciso el límite entre la vida y la no vida, los distintos tipos de muerte descritos por la ciencia médica en su omnipotente tarea hacen que los familiares no tengan más elección que confiar en el dictamen, el momento trascendental no es más que otro diagnóstico: exitus, muerte cerebral, etc.

Las representaciones artísticas de la muerte, tan comunes en el medievo, comienzan a desaparecer en el Siglo XIX. Es fundamental que todo pase lo más desapercibido y rápido posible, discreción al máximo, ¡Que no se enteren los niños!. Las no tan antiguas manifestaciones públicas de luto van desapareciendo, la ropa negra, el comportamiento, etc. Ahora todo ello pasa a formar parte de lo sórdido, lo macabro y casi patológico. La pena se tiene que llevar por dentro, que la sociedad no se vea alterada, "The show must go on" cantaba Freddie Mercury poco antes de "irse".

"La muerte se ha vuelto innombrable. Todo sucede ahora como si ni yo ni tu ni los que me son caros fuéramos mortales" (Ariés 2000 p 101). Nuestra vida ya no se deja en manos del destino, el ser humano moderno necesita controlarla hasta el punto de negar que ésta es finita. Un nuevo mito moderno, la inmortalidad, que se materializa en acciones como la criogenización del cuerpo o de partes como la cabeza o más concretamente el cerebro, que se llevan a cabo por empresas especializadas que venden la ilusión de que la ciencia todopoderosa del futuro será capaz de devolver la vida a un puñado de células (eso es lo que parece que somos).

\section{El problema del duelo.}

¿Cómo es posible que aún estando las cosas de la muerte solapadas y ocultas, carentes del excesivo dramatismo de otras épocas, sea mayor su impacto emocional ahora que antes? Actualmente la vivencia de la pérdida se exige que sea lo más privada posible, no vaya a contaminar el normal devenir de los acontecimientos. Antiguos parámetros de exhibición social no son ya válidos.

Existe un rechazo al duelo en la sociedad moderna. Los vivos no deben ser perturbados por un hecho tabú. Está mal visto exagerar los sentimientos. Prolongar las lágrimas más de lo debido y sobre todo el público. La vivencia del duelo en privado es casi una exigencia actual.

En nuestra cultura mediterránea el dolor por el duelo manifestado públicamente ha sido absolutamente legítimo; incluso las manifestaciones casi histéricas eran prueba necesaria para demostrar el afecto al ser perdido. Los alardes de luto no hace mucho eran objeto de control social y símbolos necesarios. Prendas de color negro, una determinada actitud pública, etc., son todavía apreciables en algunos ámbitos rurales de nuestra geografía.

La pena se esconde. No se exterioriza. La privación del luto ritual tiene sus consecuencias en la vivencia posterior del duelo no superado, y se puede relacionar con la falta de aceptación del hecho de la muerte del otro. Alteraciones anímicas, depresión y sentimientos de tristeza que se prolongan en el tiempo más allá de lo considerado normal son manifestaciones de la progresiva erradicación del ritual del luto. Actos como la incineración, en opinión del autor, son un exponente del deseo de desembarazarse lo antes posible del muerto, del culto a los cementerios y el peregrinaje que ello conlleva.

El carácter aparentemente traumático y exagerado del luto público tiene, sin embargo, un efecto contrario y lo que parece que resulta verdaderamente traumático es no vivirlo. Esconderlo. En los momentos de duelo es cuando más apoyo de la red social se requiere y paradójicamente es negado por la estampida que provoca el tabú de todo aquello que tiene que ver con la muerte, quedando ésta expulsada de la vida cotidiana y recluida institucionalmente en los hospitales y residencias, verdaderos santuarios de la muerte.

\section{El papel de la enfermera. El acompañamien- to. Reflexión crítica.}

A lo largo de estas líneas hemos podido ver que los modos de "vivir" la muerte han cambiado; también los lugares dónde se llevan a la gente a morir. Retomando el hilo argumental de este artículo y según se desprende de las investigaciones históri- 


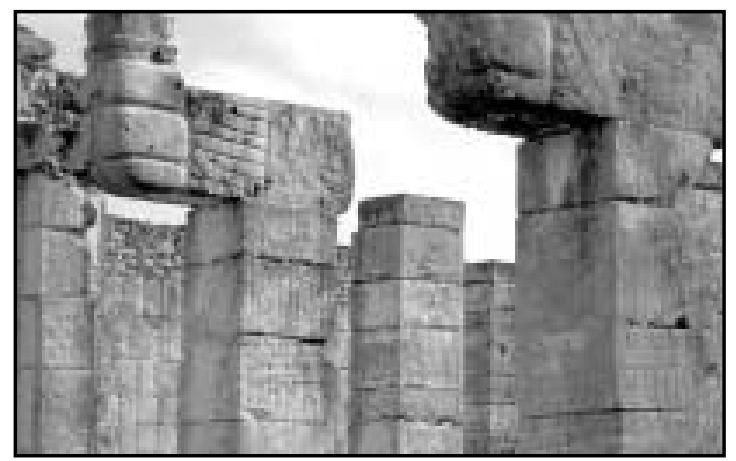

cas que en él se exponen, podríamos considerar como más humana una muerte esperada y consciente, en el propio domicilio, en la propia cama, rodeado de personas queridas y con asistencia espiritual del tipo que sea. Para nuestra mentalidad científico-técnica y como profesionales de la salud esto parece aberrante y falto de contenido. ¿Y la asistencia sanitaria?, ¿Y el problema del dolor?, ¿Y si hay que poner medicación o sondas?, ¿Haría falta un psicólogo?, ¿Tendríamos que facilitar ansiolíticos a los parientes?, ¿Quién certificaría la muerte?. Teniendo todo esto en cuenta parece mentira que la humanidad haya podido morir en paz sin supervisión sanitaria hasta nuestros días. Lo mismo ocurre con otros tantos ámbitos de nuestra existencia. Cómo hemos llegado hasta aquí, parece un milagro, sin ecografías, sin ácido fólico, sin episiotomías, sin cesáreas...

La muerte es un hecho natural, al igual que la vida, al igual que la enfermedad, las desgracias y las alegrías, todo ello forma parte del capricho o del misterio que engloba nuestra existencia. La aceptación de la finitud (por lo menos material)del ser humano es el primer paso para considerar que nuestra labor en el campo de los cuidados en los últimos momentos no debe tomar más protagonismo del necesario. El protagonismo debe ser enteramente de la persona que yace moribunda y de nadie más. La habitual forma de desempeñar la labor de los sanitarios suele pasar por el paternalismo y el pensar desde nuestra perspectiva(con una formación enteramente científica y pobremente humanística) qué es lo mejor para el cliente, o mejor dicho para el considerado "paciente"(y por ende sujeto pasivo), otorgando preponderancia a aspectos técnicos, de monitorización, sintomáticos o de recuperación de órganos y funciones corpo- rales más que a los deseos y necesidades reales en un contexto lamentablemente de despedida de este mundo. Evidentemente que no se puede desatender el dolor, los cuidados corporales y el resto de necesidades básicas de la persona, me refiero a que una percepción distinta del ser humano clama al cielo; desde la noción holística de hombre se debe priorizar y humanizar este hecho medicalizado para reconvertirlo en lo que siempre ha sido, una persona en fase de despedida, no un objeto susceptible o no de aplicación de procedimientos, reanimar o diagnosticar.

En la realidad sanitaria y social actual lo más lógico y demandado, incluso por los propios familiares y el sujeto, es acudir a un centro hospitalario cuando se sospecha la cercanía de la muerte. Tal es la fuerza con la que la medicina incrusta su poder en el subconsciente colectivo. Cuando esto ocurre debemos enmarcar nuestras acciones dentro de las consideraciones éticas que tienen en cuenta el derecho a la información, el consentimiento informado, la participación del sujeto como persona libre y autónoma en las decisiones médicas y sobre todo el derecho a tener una muerte digna, considerada ésta como humana, natural, sin sufrimientos añadidos, sin medidas desproporcionadas ni encarnizamiento terapéutico fútil, y recibiendo cuidados paliativos suficientes.

Sobre quienes toman las decisiones que afectan al sujeto se podría decir que conforman un triángulo en cuyos vértices se encuentran, el interesado, su familia y el médico, con un peso variable y distinto. La enfermera tiene una función más importante de lo que en un principio se podría pensar en este proceso que debería tener al "paciente" como principal agente en la toma de decisiones después de una información clara y veraz que en la mayoría de los casos es sumamente complicada, teniendo en cuenta lo expuesto anteriormente sobre el principal tabú de nuestro tiempo(a ver quién es el guapo que le dice: $\mathrm{Su}$ hora está próxima, ¿quiere morir en esta sala o en su domicilio?). Siendo el personal enfermero el que asiste normalmente al sujeto y a la familia en los últimos momentos, debemos tener claro que nunca debemos suplantar la función de un pariente o amigo que acompaña, ni entorpecer que, si el individuo lo desea, se encuentre acompañado de cuantos familiares requiera. Proporcionar el 
ambiente propicio, respetar y si es posible facilitar la asistencia religiosa, así como acompañar y apoyar con nuestra presencia a la persona si ésta se encuentra sola, son medidas tan importantes o más que otros procedimientos técnicos, fluidoterápicos, de monitorización o rutinarios de un hospital. Como afirma Jaime Sanz en relación con el sufrimiento que empuja al moribundo a desear cuanto antes la muerte: "El acompañamiento y la presencia vigilante son dos antídotos potentes contra las peticiones de dimitir de la vida". (Sanz. 2001)

Debemos conocer que existen otras formas alternativas de tratar a las personas en su lecho de muerte. El movimiento Alemán Hospiz, contrario a la eutanasia y favorable a la medicina paliativa y del "acompañamiento" tiene una concepción respetuosa que confiere a la muerte del sujeto ese cariz sagrado del que ha sido desposeída en la modernidad. Posee hogares y servicios ambulantes con el fin de "paliar y acompañar" personalmente a los individuos en fase terminal hasta su fin natural.

Habrá que ir tomando nota...

\section{REFERENCIAS BIBLIOGRÁFICAS}

- Ariés P.(1999). El hombre ante la muerte. Taurus, Madrid.

- Ariés P.(2000). Historia de la muerte en occidente. El acantilado, Barcelona.

- Gálvez Toro, A.(2004). La medicina bajo sospecha. Fundación Index, Granada.

- Illich Ivan.(1975).Némesis médica. La expropiación de la salud. Barral Editores, Barcelona.

- Márquez S., Meneu R.(2003). La medicalización de la vida y sus protagonistas. En Revista GCS. Verano; 5(2):47. Disponible en http://www.iiss.es/gcs/gestion16.pdf. (Consultado el 23.07.05).

- Pascal, B.(1995). Pensamientos. Elogio de la contradicción. Temas de hoy, Madrid.

- Sanz Ortiz J.(2001).Cuidados Paliativos. En Bioética en ciencias de la salud (Espejo Arias M.D., Castilla García A., editores). Asociación Alcalá, Granada.

- Thomas H. Muerte a petición. ¿Caridad o crimen? Reflexiones sobre la filosofía de Anselm Winfried Müller. Web de la Asociación Española de Bioética y Ética Médica. Disponible en http://www.aebioetica.org /rtf/B2\%20Muerte\%20a\%20peticion\%20Bio.pdf (Consultado el 21.07.2005).

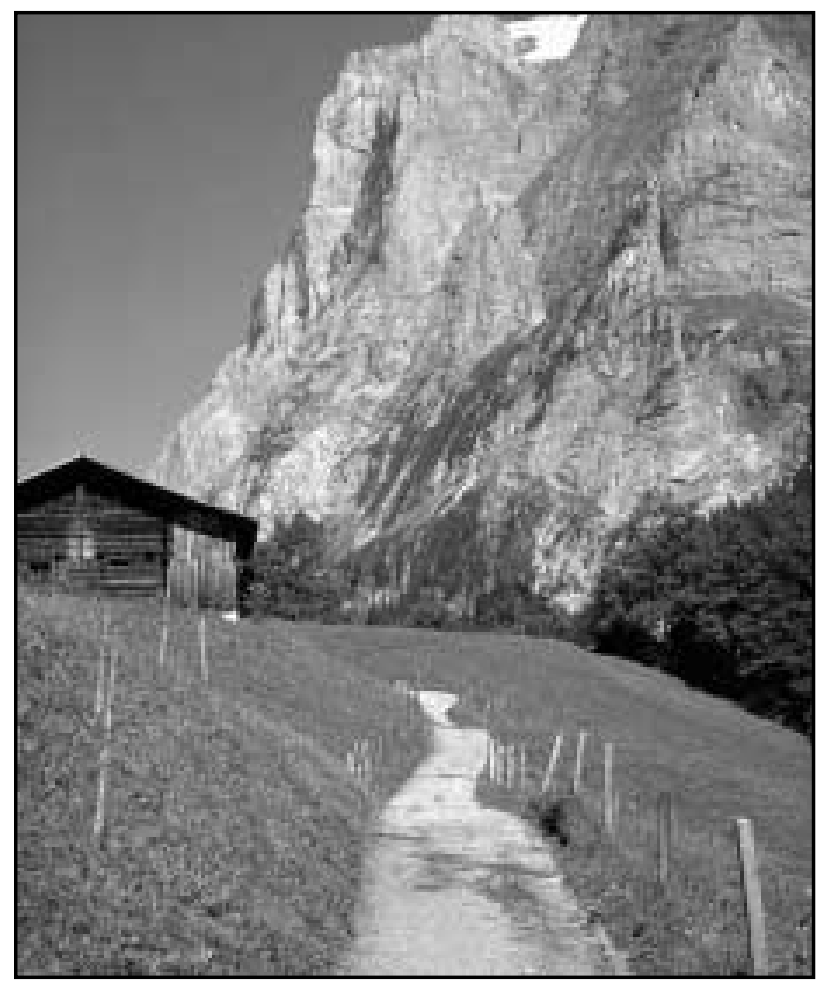

